\title{
Rheological Behavior of Renewable Polyethylene (HDPE) Composites and Sponge Gourd (Luffa cylindrica) Residue
}

\author{
Viviane Alves Escócio, ${ }^{1}$ Elen Beatriz Acordi Vasques Pacheco, ${ }^{1}$ \\ Ana Lucia Nazareth da Silva, ${ }^{1}$ André de Paula Cavalcante, ${ }^{2}$ and Leila Léa Yuan Visconte ${ }^{1}$ \\ ${ }^{1}$ Instituto de Macromoléculas, Universidade Federal do Rio de Janeiro (UFRJ), Avenida Horácio Macedo, \\ 2.030 Centro de Tecnologia, Prédio do Bloco J, 21941-598 Rio de Janeiro, RJ, Brazil \\ ${ }^{2}$ Instituto de Química, Universidade do Estado do Rio de Janeiro (UERJ), Rua São Francisco Xavier, 524 Maracanã, \\ Pavilhão Haroldo Lisboa da Cunha, Sala 310, $3^{\circ}$ Andar, 20550-900 Rio de Janeiro, RJ, Brazil
}

Correspondence should be addressed to Viviane Alves Escócio; vivi75@ima.ufrj.br

Received 26 February 2015; Accepted 27 April 2015

Academic Editor: Saiful Islam

Copyright (C) 2015 Viviane Alves Escócio et al. This is an open access article distributed under the Creative Commons Attribution License, which permits unrestricted use, distribution, and reproduction in any medium, provided the original work is properly cited.

\begin{abstract}
The present study reports the results of rheological behavior of renewable composites, based on a matrix of high density polyethylene (HDPE), made from ethanol distilled from sugarcane, and lignocellulose filler from waste generated in the processing of sponge gourds for bathing use. The composites were prepared with 10,20,30, and 40\%wt of filler in a twin-screw extruder. The materials were analyzed in a parallel plate rheometer and a melt-flow indexer. The composite morphology was determined by scanning electron microscopy. The composite viscosity increased with filler content, suggesting possible formation of filler agglomerates. This result was confirmed by Cole-Cole diagrams.
\end{abstract}

\section{Introduction}

Knowledge of the rheological properties of melted polymers is important because it permits selecting the best material for a determined application and processing technique [1]. Molar mass, size distribution of macromolecules, number of structural conformations, and the possible entanglement of polymer chains are factors responsible for the large differences in flow between various polymers during processing. The flow properties of viscoelastic fluids also depend on temperature, deformation rate, and processing time [2].

Besides these aspects, during processing, by either extrusion or injection molding, polymers are subjected to various types of deformation due to the complex geometry of the devices used. Rheological testing provides information on the deformations and strains of polymers and their composites under flow conditions, to enable understanding and predicting their final morphology and thus their properties [3].

There are only a few reports in the literature on the rheological behavior of HDPE composites of fossil origin (called conventional HDPE here) combined with cellulose.
To the best of our knowledge, there are no published studies of composites made of totally renewable polyethylene. González-Sánchez et al. [4] studied the rheological behavior of composites made of HDPE or polypropylene (PP) with $10,25,40$, and $48 \%$ by weight of cellulose fiber before and after five reprocessing cycles. The fiber used was eucalyptus pulp. The effects of shear rate, fiber content, and type of matrix were analyzed in the virgin and reprocessed composites. The rheological data, obtained by capillary rheometry, scanning electron microscopy, and thermogravimetry, showed a decline in viscosity of the HDPE reprocessed at low shear rates. This decrease was more pronounced in the composites containing higher fiber concentrations, due to the thermal degradation of the fibers at low shear rates (lower than $100 \mathrm{~s}^{-1}$ ). The authors also observed a greater loss of pseudoplasticity of the PP composites than those made with HDPE. In another study of HDPE composites, Li and Wolcott [5] also assessed the rheological properties with a capillary rheometer and used different cellulose filler, from maple and pine logs with different diameters. The authors observed 
the wall slip velocity and its dependence on the wood content, type of filler, and shear stress. According to literature [6, $7]$, the wall slip effects are generally observed in the flow of highly viscous two-phase materials in rheometers, pipes, or any channel with smooth walls. Near the smooth, solid boundary, the local microstructure is depleted because the suspended particles could not penetrate the solid walls. $\mathrm{Li}$ and Wolcott [5] also analyzed the extensional flow, finding that the extensional viscosity is more dependent on the wood content than on the species. Mohanty and Nayak [8] studied the viscoelastic behavior of composites of HDPE and sisal fiber, also using capillary rheometry. They observed that the composites viscosity increased with the incorporation of fiber, a finding also reported by other researchers, and that treatment of the polyethylene with maleic anhydride caused an increase in the viscosity due to the better adhesion of the polymer matrix to the fiber, which was confirmed by scanning electron microscopy. Besides this, other dynamic properties (storage modulus, $G^{\prime}$, loss modulus, $G^{\prime \prime}$, and $\tan$ delta $\delta$ ) also increased with cellulosic reinforcement.

The objective of this study was to investigate the rheological behavior in a parallel plate rheometer of a totally renewable composite made of polyethylene derived from ethanol with different concentrations of added filler from sponge gourd processing residue $(10,20,30$, and $40 \% \mathrm{wt})$.

\section{Experimental}

2.1. Raw Materials. The high density polyethylene (HDPE) SHC 7260 (Braskem, Brazil) was obtained from sugarcane ethanol. Its density is $0.959 \mathrm{~g} / \mathrm{cm}^{3}$ and the melt-flow index is $7.2 \mathrm{~g} / 10 \mathrm{~min}\left(190^{\circ} \mathrm{C} ; 2.16 \mathrm{~g}\right)$. The sponge gourd residue (cellulosic filler) was provided by the company Bushings Bonfim, state of Minas Gerais, Brazil. This filler has density of $1.3 \mathrm{~g} / \mathrm{cm}^{3}$, particle size of $<0.15 \mathrm{~mm}$, and moisture content of $10.7 \%$ by weight.

2.2. Composite Preparation. The HDPE composites with 10, 20,30 , and $40 \%$ wt of sponge gourd residue were processed in a Tecktril model DCT- 2 corotating interpenetrating twinscrew extruder. The cellulosic filler was conditioned before processing in an oven with air circulation for 24 hours at a temperature of $60^{\circ} \mathrm{C}$. Before addition of the material in the extruder, the polymer and the milled filler were manually premixed. The extrusion conditions were as follows: rotating speed of $300 \mathrm{rpm}$; feeder rotation of $15 \mathrm{rpm}$; temperature in processing zone $1: 90^{\circ} \mathrm{C}$, zones 2 to $5: 140^{\circ} \mathrm{C}$, zones 6 to 9: $160^{\circ} \mathrm{C}$, and head: $180^{\circ} \mathrm{C}$. The obtained pellets were heated at $60^{\circ} \mathrm{C}$ to remove moisture.

\subsection{Composite Characterization}

2.3.1. Melt-Flow Index (MFI). Before performing this test, the samples, in the form of pellets, were dried in an oven with air circulation for 24 hours at $60^{\circ} \mathrm{C}$. The melt-flow index (MFI) (ASTM D1238) [9] was measured in a Dynisco Kayeness Polymer Test Systems model LMI 4003 melt indexer.
2.3.2. Melt Rheology. The oscillatory flow measurements, namely, the complex viscosity, $\eta^{*}$, the storage modulus, $G^{\prime}$, and the loss modulus, $G^{\prime \prime}$, of the pure HDPE and its composites were determined in a TA Instruments rheometer, model AR 2000. A strain sweep test was initially conducted to determine the linear viscoelastic region of the materials. Dynamic frequency sweep test (strain: 0.3\%; frequency: 0.1 to $600 \mathrm{rad} / \mathrm{s}$; and temperature at $170^{\circ} \mathrm{C}$ ) was subsequently performed to determine the dynamic properties of the materials, using a parallel-plate geometry with $25 \mathrm{~mm}$ of diameter and a gap set at $0.5 \mathrm{~mm}$.

Stress relaxation experiments are the fundamental way in which relaxation modulus, $G(t)$, can be defined. The relaxing stress data are used to determine $G(t)$ directly,

$$
G(t)=\frac{\tau(t)}{\gamma_{0}} .
$$

The stress relaxation tests were conducted at a constant strain of $0.3 \%$ and at a temperature of $170^{\circ} \mathrm{C}$.

2.3.3. Surface Morphology and Dispersion Characteristic. The morphology of the samples was examined by SEM using a Jeol model JSM-6510LV microscope. Gold sputtering of the specimens fractured in the impact test was carried out using a Denton Desk V vacuum sputter system. The samples were fractured at room temperature.

\section{Results and Discussion}

3.1. Melt-Flow Index (MFI). The melt-flow index (MFI) is a physical parameter that is widely used to evaluate the ability of a polymer to flow when melted. The MFI value (Figure 1) declined as the sponge gourd residue concentration increased, due to the increased viscosity of the HDPE/filler system compared to the pure HDPE. With the addition of $10 \%$ by weight of cellulose, the MFI decreased by $19 \%$, while for a filler content of $20 \%$ wt the decline was $43 \%$ and with addition of $40 \%$ wt the decrease was $83 \%$ in relation to the pure HDPE.

By the rule of mixtures criterion [10], the addition of $10 \%$ wt of cellulose filler should cause a decrease of $10 \%$ in the MFI, but this did not occur. Instead, the result of the property for this composition was $6.8 \mathrm{~g} / 10 \mathrm{~min}(20 \%$ lower than for the pure polymer). Similar MFI behavior was observed by Mohanty and Nayak [11] for conventional HDPE composites obtained from petroleum and bamboo fiber. Cellulosic fillers are incompatible with the polymer matrix and have a tendency to form aggregates during processing [12], which might further impede the flow of the polymer matrix.

3.2. Melt-State Rheology. Viscosity is one of the most commonly used parameters to investigate the behavior of polymer materials during processing, since the majority of transformation processes occur in shear flows. The measure of storage modulus $\left(G^{\prime}\right)$ and loss modulus $\left(G^{\prime \prime}\right)$, which are related, respectively, to the energy stored and dissipated during a cycle, is also widely used to study the processing of polymer materials. The storage modulus depends on the rigidity of 


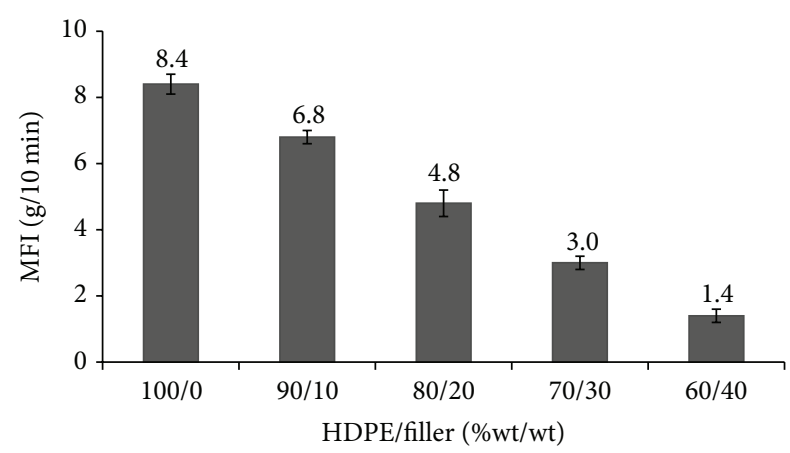

Figure 1: Melt-flow index of composites of renewable HDPE and sponge gourd filler.

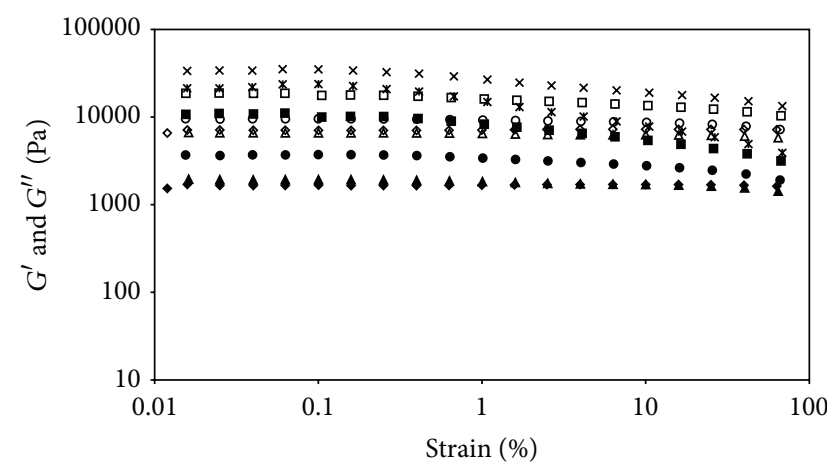

- HDPE $-G^{\prime}$

- HDPE $-G^{\prime \prime}$

- HDPE $+10 \%$ filler $-G^{\prime}$

$\triangle$ HDPE $+10 \%$ filler $-G^{\prime \prime}$

- HDPE + 20\% filler $-G^{\prime}$

- HDPE + $20 \%$ filler $-G^{\prime \prime}$

- HDPE + $30 \%$ filler $-G^{\prime}$

- HDPE + $30 \%$ filler $-G^{\prime \prime}$

$\times$ HDPE $+40 \%$ filler $-G^{\prime}$

$\times$ HDPE $+40 \%$ filler $-G^{\prime \prime}$

FIGURE 2: Strain sweep results for neat renewable HDPE and its composites containing different $\mathrm{wt} \%$ of sponge gourd filler.

the macromolecules and their entanglement, while the loss modulus depends on the bonds, which control conformational changes in chain segments and the displacement of one chain in relation to another [2]. In turn, the rheology of composites is influenced by the interactions that occur between the polymer matrix and the filler, along with the structure, size, and shape of the particles and the quality of their dispersion throughout the melted matrix [13-15].

Strain sweep tests were conducted at $170^{\circ} \mathrm{C}$ in nitrogen atmosphere with a constant frequency of $1 \mathrm{~Hz}$ and in the strain range of 0.01 to $100 \%$. As it can be seen in Figure 2, the response of all samples does not depend on the strain (both $G^{\prime}$ and $G^{\prime \prime}$ exhibit a constant plateau), and the behavior is well within the linear viscoelastic region. However, the plateau region shortens with higher cellulosic filler contents in HDPE matrix, 30 and $40 \mathrm{wt} \%$. It can also be seen that $G^{\prime \prime}$ is dominating over $G^{\prime}$ for all composites analyzed, indicating that the overall behavior is dominated by viscous segmental frictions. The composite with $10 \mathrm{wt} \%$ of filler exhibits quite similar trend as neat HDPE. As filler content increases, the gap between $G^{\prime \prime}$ and $G^{\prime}$ values decreases, showing that viscous behavior becomes less pronounced with higher filler

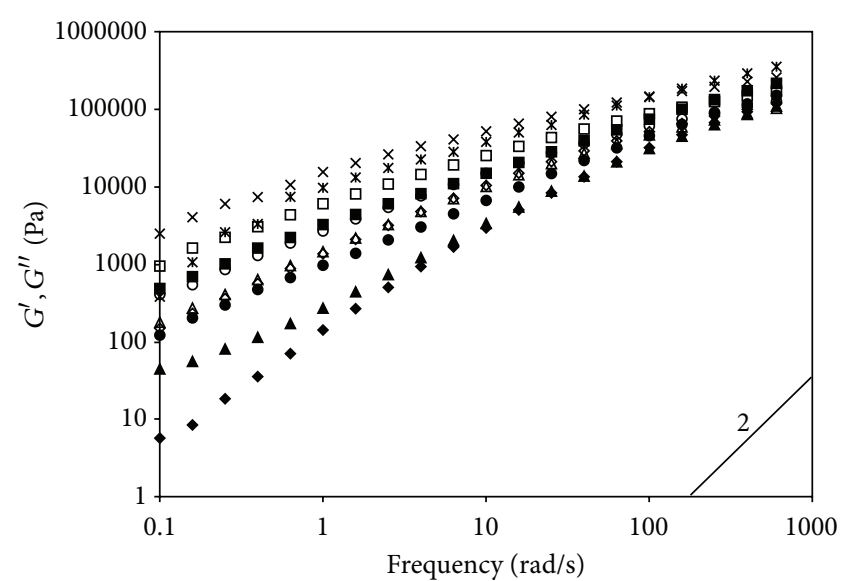

- HDPE $-G^{\prime}$

- HDPE - $G^{\prime \prime}$

- HDPE $+10 \%$ filler $-G^{\prime}$

$\triangle \mathrm{HDPE}+10 \%$ filler $-G^{\prime \prime}$

- $\mathrm{HDPE}+20 \%$ filler $-G^{\prime}$

- HDPE + $20 \%$ filler $-G^{\prime \prime}$

- HDPE + 30\% filler $-G^{\prime}$

- $\mathrm{HDPE}+30 \%$ filler $-G^{\prime \prime}$

* HDPE + $40 \%$ filler $-G^{\prime}$

$\times$ HDPE $+40 \%$ filler $-G^{\prime \prime}$

FIGURE 3: Variation of the storage modulus, $G^{\prime}$, and loss modulus, $G^{\prime \prime}$, as a function of frequency for neat renewable HDPE and its composites containing different $w t \%$ of sponge gourd filler.

loading in HDPE matrix and a tendency to a gradual switch from viscoelastic liquid-like to solid-like behavior occurs. From the above experiments, the strain was then set at $0.3 \%$ to ensure that the response of all materials would be within the linear viscoelastic region.

Small amplitude oscillatory shear measurements were performed at $170^{\circ} \mathrm{C}$ and $0.3 \%$ strain. The dynamic moduli, $G^{\prime}$ and $G^{\prime \prime}$, are showed in Figure 3 for HDPE and HDPE/filler composites. The obtained behavior in frequency sweep is in accordance with the results of strain sweep. In fact, HDPE and HDPE composites exhibit $G^{\prime \prime}>G^{\prime}$ in a wide frequency range, indicating that the materials present a pronounced viscous behavior; however, as filler content increases, the gap between $G^{\prime \prime}$ and $G^{\prime}$ tends to decrease and a characteristic solid-like behavior tends to occur.

According to Jiang et al. [16], a homopolymer with narrow molecular weight distribution presents a characteristic terminal behavior of $G^{\prime} \propto \omega^{2}$. In the present study, the neat HDPE did not deviate significantly from the standard terminal behavior, $G^{\prime} \propto \omega^{1.18}$. As filler was added in HDPE matrix, a deviation from $G^{\prime} \propto \omega^{0.96}$ for $10 \mathrm{wt} \%$ filler to $G^{\prime} \propto \omega^{0.69}$ for $40 \mathrm{wt} \%$ filler was observed. This behavior indicates a solid-like viscoelastic behavior as filler content is increased. In other words, the addition of sponge gourd filler in the HDPE matrix prevents a complete relaxation due to physical jamming.

The frequency at which $G^{\prime}$ and $G^{\prime \prime}$ moduli curves cross each other reflects the transition from viscous to elastic response of the viscoelastic melts [17].

Table 1 shows the crossover point $\left(G^{\prime}=G^{\prime \prime}\right)$ and the frequency values, $\omega_{c}$, where these cross points occurred.

The results show that a decrease of up to $20 \mathrm{wt} \%$ of filler in the HDPE matrix in the cross point and in the crossover 
TABLE 1: Modulus and frequency values in the cross point $G^{\prime} / G^{\prime \prime}$ for the compositions analyzed.

\begin{tabular}{lcc}
\hline Sample codes & $\begin{array}{c}\text { Cross point, } \\
G^{\prime}=G^{\prime \prime}(\mathrm{Pa})\end{array}$ & $\omega_{c}(\mathrm{rad} / \mathrm{s})$ \\
\hline HDPE & 101700 & 398 \\
HDPE + 10\% filler & 89590 & 398 \\
HDPE + 20\% filler & 76340 & 158 \\
HDPE + 30\% filler & 108400 & 158 \\
HDPE + 40\% filler & 148900 & 100 \\
\hline
\end{tabular}

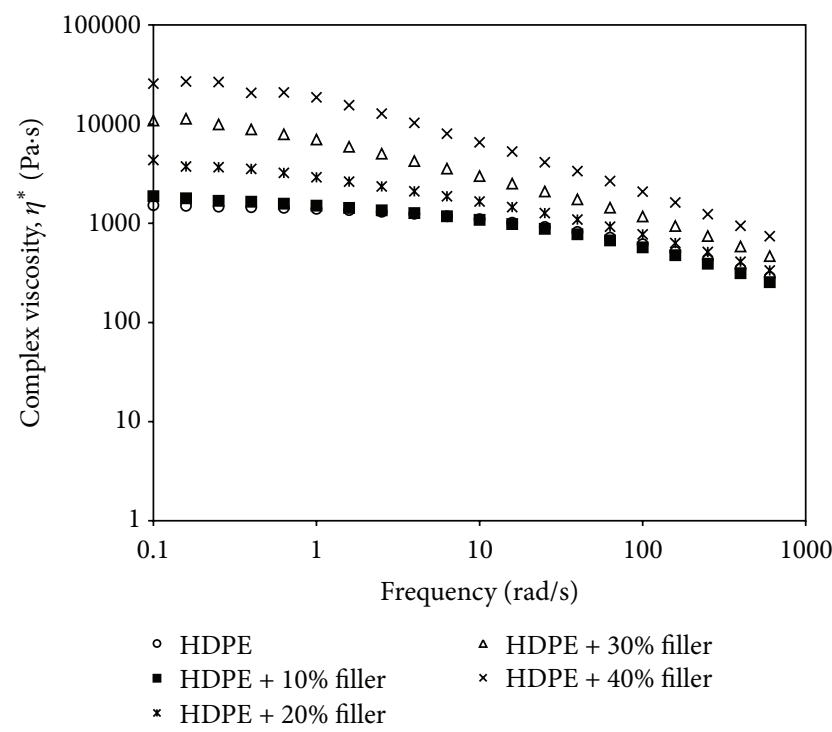

FigURE 4: Variation of the complex shear viscosity as a function of frequency for neat renewable HDPE and its composites containing different wt $\%$ of sponge gourd filler.

frequency values was observed. It indicates that materials with more elastic behavior tend to be produced, but at the same time the composites present a shear thinning behavior as frequency increases. As filler content was further added to HDPE matrix (30 and $40 \mathrm{wt} \%$ ) an increasing cross point value was observed, while crossover frequency values still decreased. This behavior can be related to a characteristic of solid-like behavior more pronounced in these high load composites, as compared with the other compositions. Probably it occurred due to the tendency to form aggregates during processing when higher filler contents are present, which might further hinder the HDPE matrix flow, as mentioned before.

The variation of the complex viscosity as a function of frequency (Figure 4) is another way to show these latest results.

Figure 4 shows that neat HDPE and $10 \mathrm{wt} \%$ filler composition present similar flow behavior in the whole frequency range analyzed. Only at low frequency values, the composite presents a slightly higher viscosity values in relation to neat HDPE. When $20 \mathrm{wt} \%$ of filler was added, higher viscosity values were obtained, but a frequency-thinning characteristic can also be observed, reaching similar flow behavior in

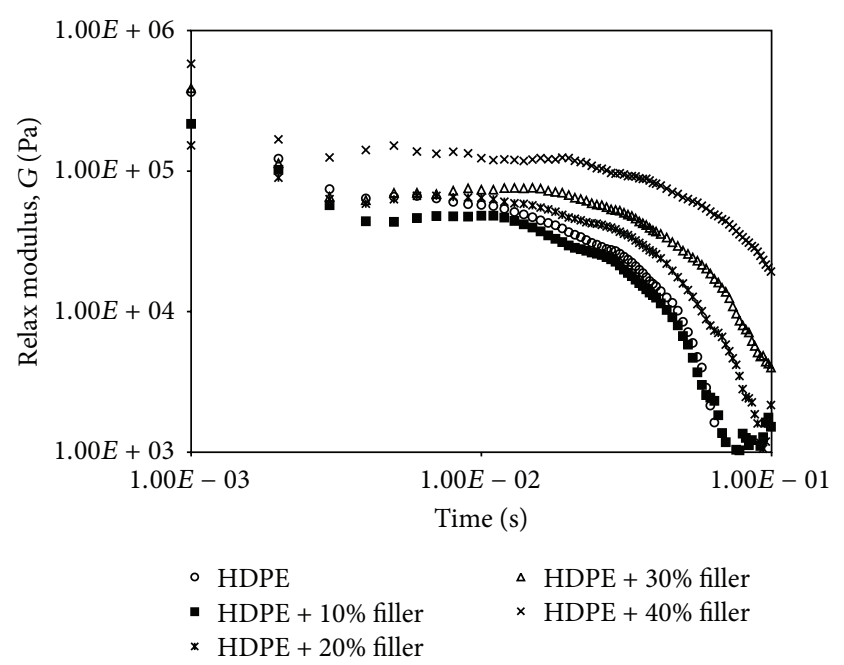

FIGURE 5: Variation of relaxation modulus with time for neat renewable HDPE and its composites containing different wt\% of sponge gourd filler. The experiments were performed at a constant strain of $0.3 \%$ in nitrogen atmosphere.

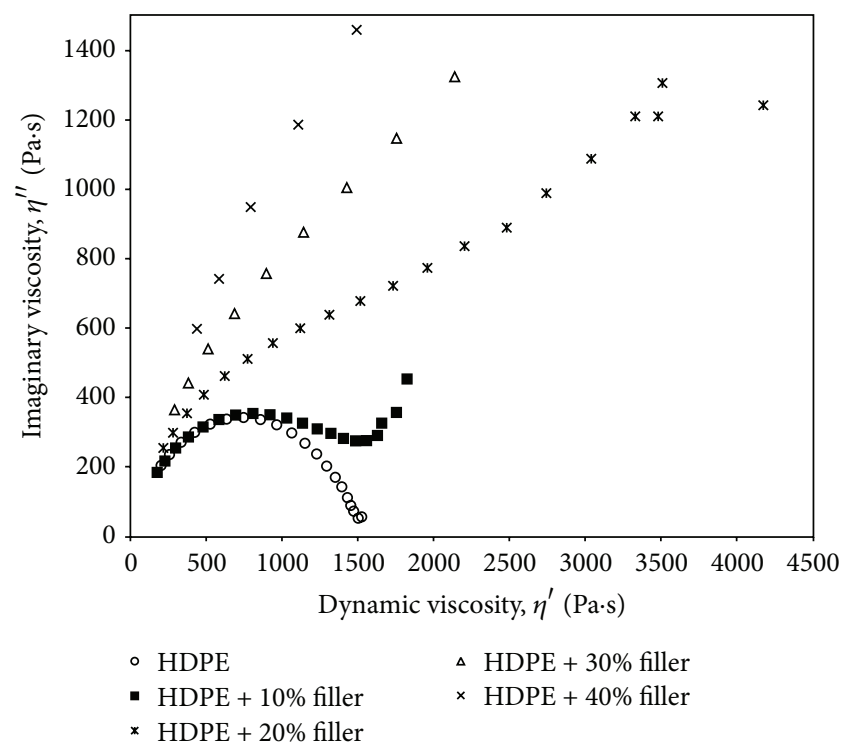

Figure 6: Cole-Cole representation of the viscoelastic properties of neat HDPE and HDPE/filler composites.

relation to the neat HDPE and $10 \mathrm{wt} \%$ filler composition at higher frequencies. Probably it occurred due to the fact that up to $20 \mathrm{wt} \%$ of filler aggregates can disentangle, allowing polymer chain to flow. However at higher filler contents, disentanglement processes become more difficult in the frequency range analyzed and thus higher viscosity values were observed.

The variation of the relaxation modulus with time is reported in Figure 5. The results show that $G(t)(G(t)=$ $\left.\sigma(t) / \gamma_{0}\right)$ of HDPE presents a behavior similar to a polymer with high molecular weight and narrow distribution; that is, a plateau zone appears in which the modulus is nearly 


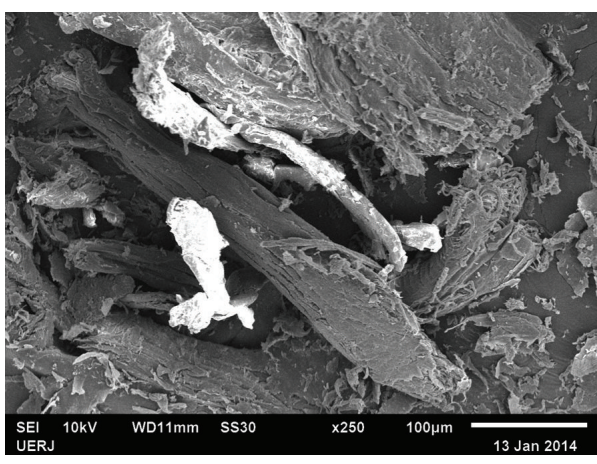

(a)

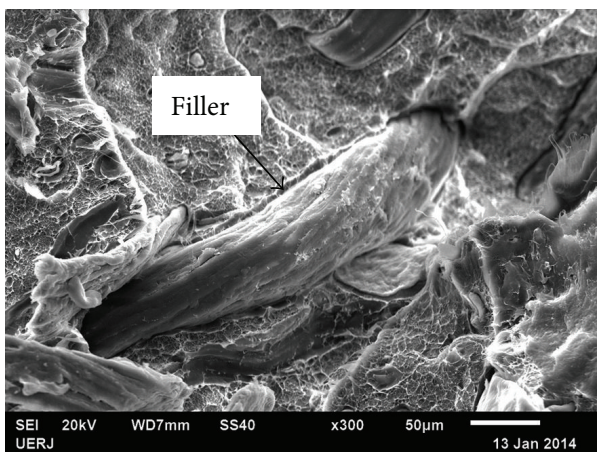

(c)

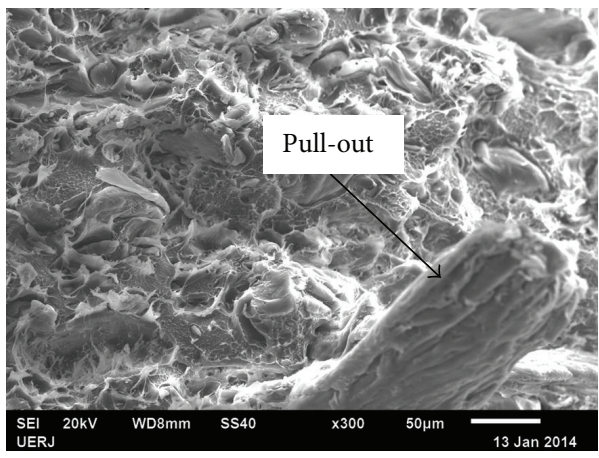

(e)

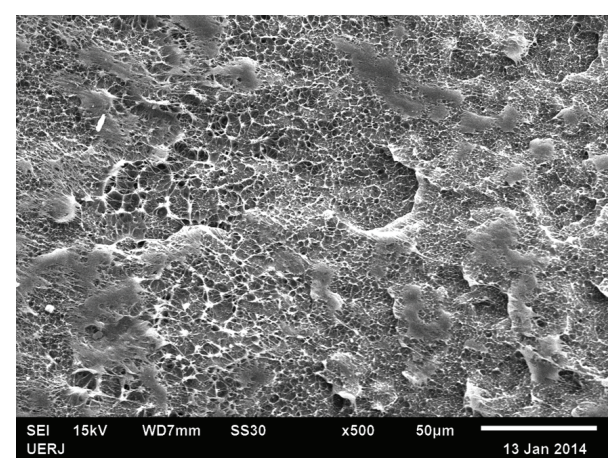

(b)

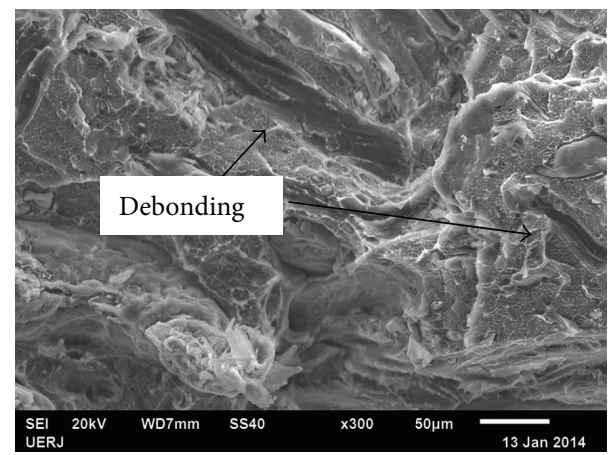

(d)

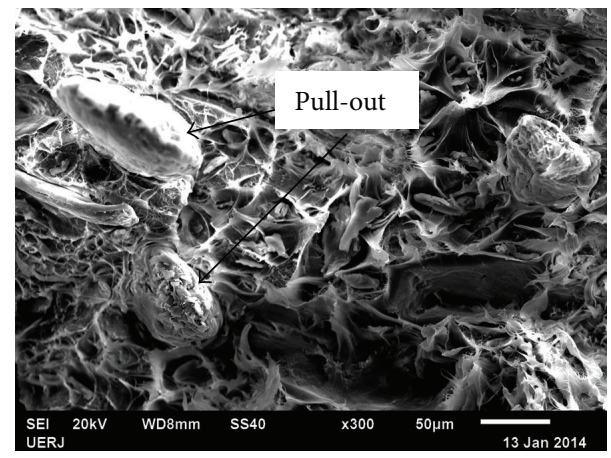

(f)

FIGURE 7: SEM micrographs of fracture surfaces for the following samples: sponge gourd residue with particle size $<0.15 \mathrm{~mm}$ (a), renewable HDPE (b), and renewable HDPE/cellulosic filler composites: (c) 90/10\%wt/wt, (d) 80/20\%wt/wt, (e) 70/30\%wt/wt, and (f) 60/40\%wt/wt.

constant. At longer times, flow occurs and the $G(t)$ curve moves towards a "terminal zone," where the modulus relaxes at sufficiently long times. For HDPE/filler composite with $10 \mathrm{wt} \%$ filler a similar behavior is observed in relation to neat HDPE for long times. As filler was added in HDPE matrix, $G(t)$ extends to long time and the magnitude of $G(t)$ value increases with the filler concentration. This behavior is another indication for the formation of filler aggregates (such as "temporary network") when higher filler contents are added, hindering the occurrence of relaxation processes. At even longer periods of time, the "network" disentangles and a decrease of $G(t)$ values is once again observed.

Linear viscoelastic characteristics derived from the results of rheological measurements are also shown in a different representation in Figure 6, using the so-called Cole-Cole plots for HDPE and HDPE/filler composites. In this representation, the $\eta^{\prime \prime}$ parameter (where $\eta^{\prime \prime}=G^{\prime} / \omega$ ), the so-called imaginary viscosity, is plotted against dynamic viscosity, $\eta^{\prime}$ (where $\eta^{\prime}=G^{\prime \prime} / \omega$ ). The plot should be a perfect arc if higher order structures are absent and the relaxation behavior of the melt can be described by a single relaxation time [17]. According to Ábrányi et al. [18], studies on heterogeneous systems in melts containing network, the elastic component of viscosity $\left(\eta^{\prime \prime}\right)$ increases and the structure has a larger relation time.

Data shown in Figure 6 indicate that the addition of filler leads to an increase of the elastic behavior of the composites and larger relaxation times can be observed as increasing filler loads are added in HDPE matrix, indicating the presence of filler aggregates. 
3.3. Morphology Analysis. Figure 7 shows scanning electron microscope (SEM) images of the filler alone, with particle size smaller than $0.15 \mathrm{~mm}$, pure HDPE, and composites. Figure 7(a) shows the irregularities of the sponge gourd filler, which is characteristic of natural fibers. Figure 7 (b) shows the fracture surface of the pure HDPE, with slight roughness, after being submitted to impact resistance test, conducted at room temperature, a factor that can explain this roughness. Some displacement of fibers can be seen in Figures $7(\mathrm{c})$ and $7(\mathrm{~d})$, which increases on rising filler content, due to the low adhesion of the polymer/filler interface. Finally, Figures 7(e) and 7(f) show the pull-out of the fillers and also the greater surface roughness of the composite with $40 \% \mathrm{wt}$ filler. Filler agglomeration can be observed, corroborating the rheological results.

\section{Conclusion}

The rheological behavior of the composites comprising renewable HDPE and cellulosic filler showed that the viscosity of the system increases with higher filler content. This result suggests that the filler acts as a barrier to chain flow. According to Cole-Cole diagram, this system forms agglomerates due to the incompatibility of the matrix and filler. The melt-flow index results show values lower than expected, also corroborating the possible formation of filler agglomerates in the composite. Strain and frequency sweep analysis showed that, with the increase filler content, the gap between $G^{\prime \prime}$ and $G^{\prime}$ values decreases, showing that viscous behavior becomes less pronounced with higher filler loading in HDPE matrix and a tendency to a gradual switch from viscoelastic liquid-like to solid-like behavior occurs. The SEM micrographs allowed observing roughness at the fracture surface and fracture mechanisms in the composites such as pull-out, displacement of filler, and formation of agglomerates, a consequence of the low adhesion between the polymer matrix and cellulosic filler. These results are in accordance with rheological behavior observed. It can therefore be concluded that it is possible to obtain composites made from totally renewable polymer with good rheological properties, enabling reduction of negative environmental impacts.

\section{Conflict of Interests}

The authors declare that there is no conflict of interests regarding the publication of this paper.

\section{Acknowledgments}

The authors would like to thank Fundação de Amparo à Pesquisa do Estado do Rio de Janeiro (FAPERJ), Coordenacão de Aperfeiçoamento de Pessoal de Nível Superior (CAPES), Banco Nacional de Desenvolvimento (BNDES), Financiadora de Estudos e Projetos (FINEP), Conselho Nacional de Desenvolvimento Científico e Tecnológico (CNPq), and Center for Excellence in Recycling and Sustainable Development (in Portuguese Núcleo de Excelência em Reciclagem e Desenvolvimento Sustentável-NERDES) for financial support, and BRASKEM for supplying the renewable HDPE.

\section{References}

[1] A. S. Sarvestani, "Modeling the solid-like behavior of entangled polymer nanocomposites at low frequency regimes," European Polymer Journal, vol. 44, no. 2, pp. 263-269, 2008.

[2] S. A. Cruz, M. Farah, M. Zanin, and R. E. Bretas, "Avaliação das propriedades reológicas de blendas de PEAD virgem/PEAD reciclado," Polímeros, vol. 18, no. 2, pp. 144-151, 2008.

[3] R. E. S. Bretas and M. A. D’Ávil, Reologia de polímeros Fundidos, Edufscar, São Carlos, Brazil, 2nd edition, 2005.

[4] C. González-Sánchez, C. Fonseca-Valero, A. Ochoa-Mendoza, A. Garriga-Meco, and E. Rodríguez-Hurtado, "Rheological behavior of original and recycled cellulose-polyolefin composite materials," Composites Part A: Applied Science and Manufacturing, vol. 42, no. 9, pp. 1075-1083, 2011.

[5] T. Q. Li and M. P. Wolcott, "Rheology of HDPE-wood composites. I. Steady state shear and extensional flow," Composites Part A: Applied Science and Manufacturing, vol. 35, no. 3, pp. 303-311, 2004.

[6] Y. Cohen and A. B. Metzner, "Apparent slip flow of polymer solutions," Journal of Rheology, vol. 29, no. 1, pp. 67-102, 1985.

[7] R. Komuro, K. Kobayashi, T. Taniguchi, M. Sugimoto, and K. Koyama, "Wall slip and melt-fracture of polystyrene melts in capillary flow," Polymer, vol. 51, no. 10, pp. 2221-2228, 2010.

[8] S. Mohanty and S. K. Nayak, "Rheological characterization of HDPE/sisal fiber composites," Polymer Engineering and Science, vol. 47, no. 10, pp. 1634-1642, 2007.

[9] ASTM D1238-10, Standard Test Method for Melt Flow Rates of Thermoplastics by Extrusion Plastometer, Plastics, 08.01, ASTMAnnual Book of ASTM Standards, Philadelphia, Pa, USA, 2007.

[10] J. R. Callister and D. William, Ciência e engenharia de materiais uma introdução, LTC, Rio de Janeiro, Brazil, 7th edition, 2002.

[11] S. Mohanty and S. K. Nayak, "Short bamboo fiber-reinforced HDPE composites: influence of fiber content and modification on strength of the composite," Journal of Reinforced Plastics and Composites, vol. 29, no. 14, pp. 2199-2210, 2010.

[12] Z. N. Azwa, B. F. Yousif, A. C. Manalo, and W. Karunasena, "A review on the degradability of polymeric composites based on natural fibres," Materials and Design, vol. 47, pp. 424-442, 2013.

[13] S. Nandi, S. Bose, S. Mitra, and A. K. Ghosh, "Dynamic rheology and morphology of HDPE-fumed silica composites: effect of interface modification," Polymer Engineering and Science, vol. 53, no. 3, pp. 644-650, 2013.

[14] P. V. Joseph, Z. Oommen, K. Joseph, and S. Thomas, "Melt rheological behaviour of short sisal fibre reinforced polypropylene composites," Journal of Thermoplastic Composite Materials, vol. 15, no. 2, pp. 89-114, 2002.

[15] S. Mohanty, S. K. Verma, and S. K. Nayak, "Rheological characterization of PP/jute composite melts," Journal of Applied Polymer Science, vol. 99, no. 4, pp. 1476-1484, 2006.

[16] L. Jiang, J. Zhang, and M. P. Wolcott, "Comparison of polylactide/nano-sized calcium carbonate and polylactide/ montmorillonite composites: reinforcing effects and toughening mechanisms," Polymer, vol. 48, no. 26, pp. 7632-7644, 2007.

[17] T. F. Cipriano, A. L. N. Silva, A. H. M. F. T. Silva, A. M. F. Sousa, G. M. Silva, and C. R. Nascimento, "Rheological and 
morphological properties of composites based on polylactide and talc," Journal of Materials Science and Engineering B, vol. 11, pp. 695-699, 2013.

[18] Á. Ábrányi, L. Százdi, B. Pukánszky, and G. J. Vancsó, "Formation and detection of clay network structure in poly(propylene)/layered silicate nanocomposites," Macromolecular Rapid Communications, vol. 27, no. 2, pp. 132-135, 2006. 

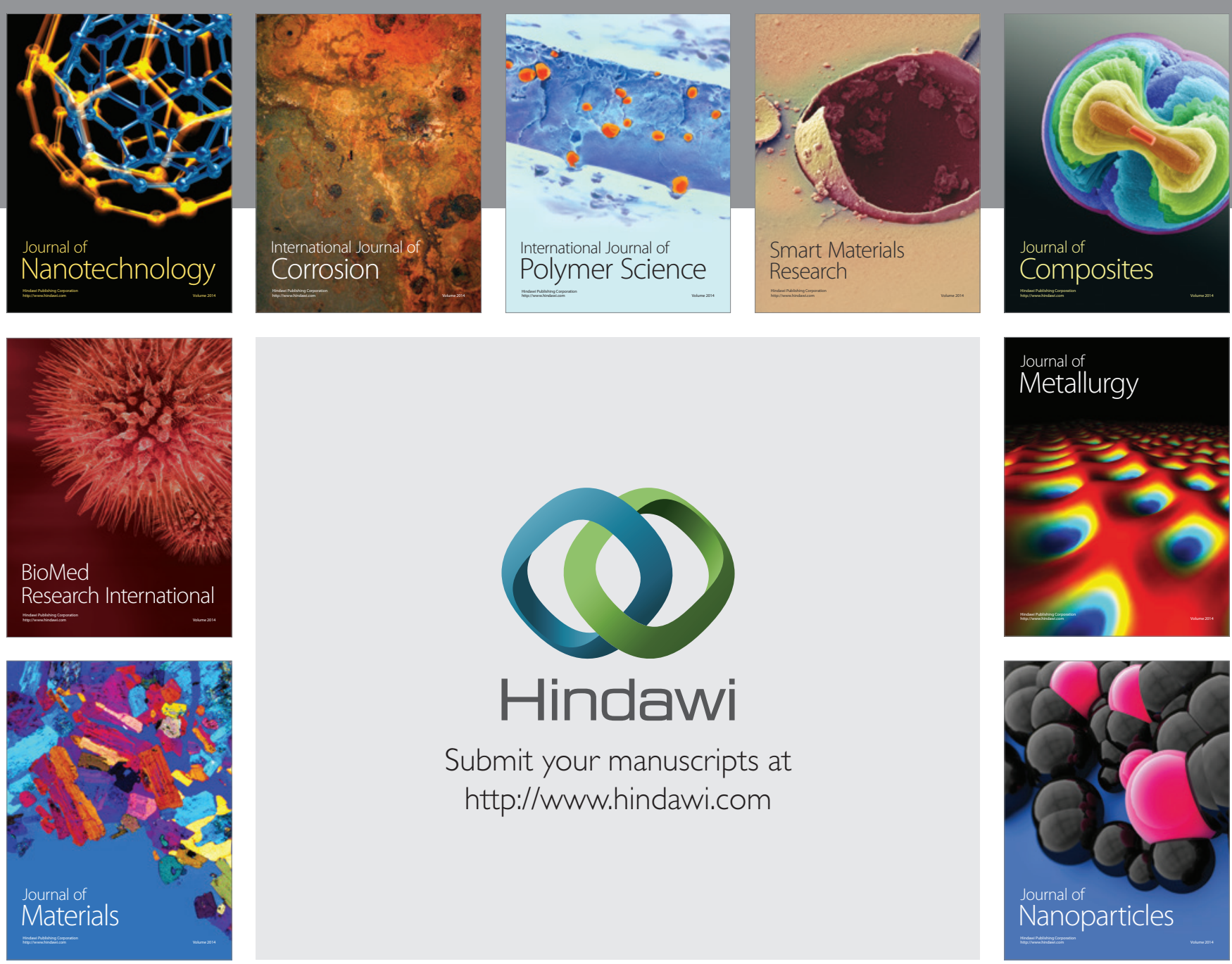

Submit your manuscripts at http://www.hindawi.com
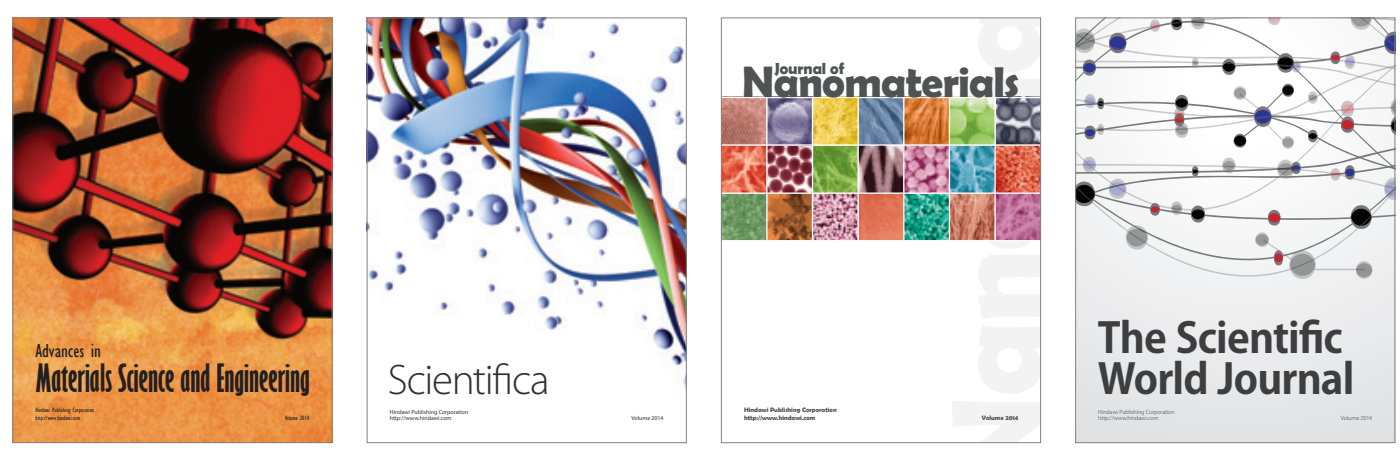

\section{The Scientific World Journal}
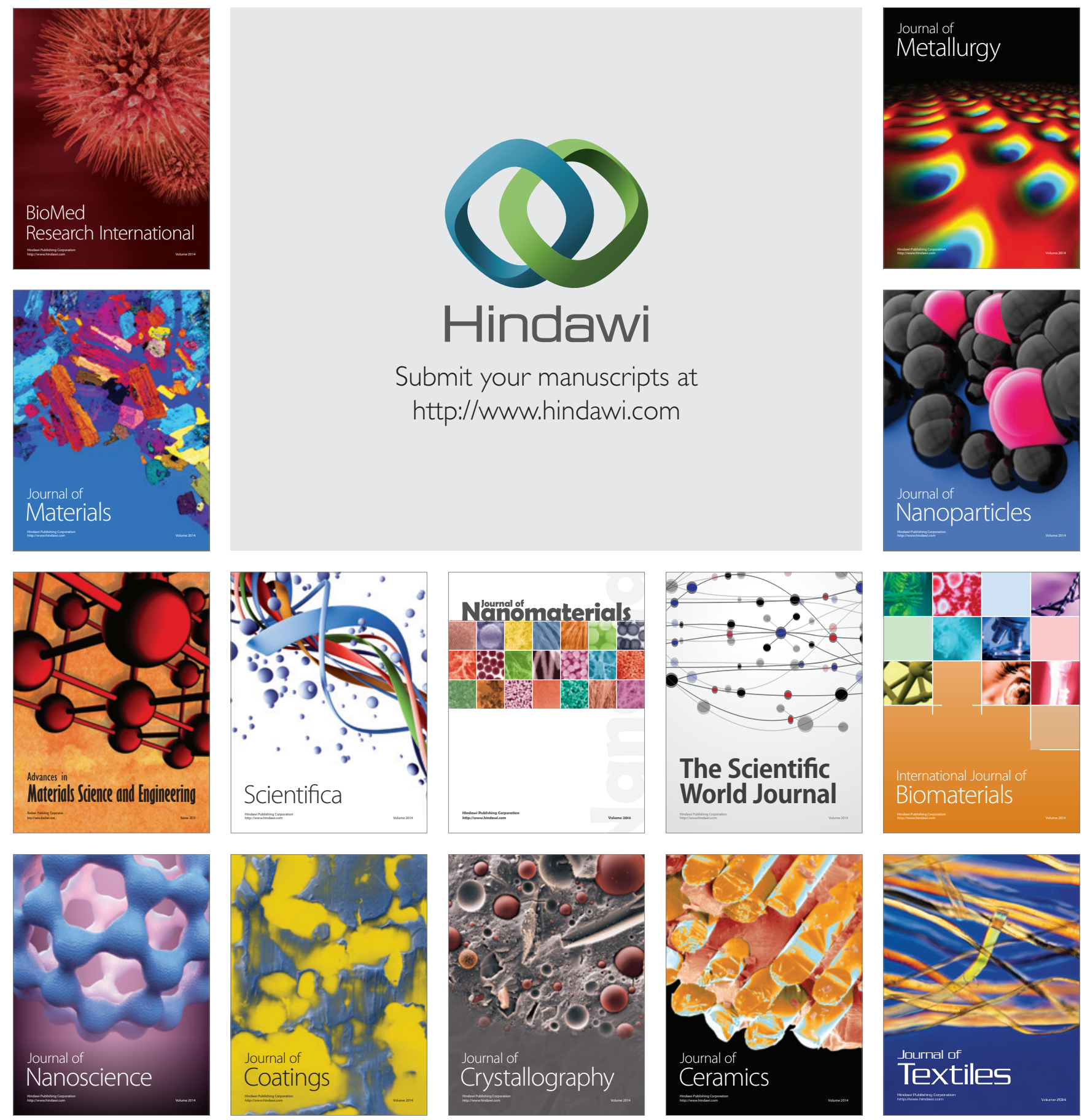